\title{
The Impact of Absa Enterprise Development on Small and Micro Enterprise Growth
}

\author{
T. A. Makhubele ${ }^{1}$, C. Nieuwenhuizen ${ }^{2}$ \\ ${ }^{1}$ ABSA Enterprise Development, Barclays Africa Group Limited, Johannesburg, South Africa \\ ${ }^{2}$ Department Business Management, University of Johannesburg, Johannesburg, South Africa
}

Email address:

Abigail.Makhubele@absa.co.za (T. A. Makhubele), cecilen@uj.ac.za (C. Nieuwenhuizen)

\section{To cite this article:}

T. A. Makhubele, C. Nieuwenhuizen. The Impact of Absa Enterprise Development on Small and Micro Enterprise Growth. Science Journal of Business and Management. Vol. 4, No. 2, 2016, pp. 42-50. doi: 10.11648/j.sjbm.20160402.14

Received: March 4, 2016; Accepted: March 28, 2016; Published: April 7, 2016

\begin{abstract}
ABSA Enterprise Development (ABSA ED), a division within Barclays Africa Group Limited (bank and finance sector), was established with the mandate to create an enabling environment that supports, advances funding and grants access to markets directed at small and micro enterprise (SME) growth and sustainability. The primary research objective was to determine the impact of the ABSA ED service on the development and growth of the SMEs that bank with ABSA and make use of ABSA ED. The secondary research objective was to identify and assess SMEs that are using the ABSA ED service and to determine their growth position by assessing business growth, competition, business strategy and business development. A quantitative research approach was adopted and included a survey in which 106 SMEs participated. Findings reveal that SMEs are positively impacted by ABSA ED interventions in business growth, strategy and development, but they lacked awareness of competition. SME strategy was significantly related to firm growth, and use of ABSA ED showed a strong positive relation of .8034, although a small effect correlation (.0149) on improving business sales/turnover. Business development indicated no significant correlation between the number of training opportunities the entrepreneur attended and the growth levels of the firm. The age of 55.2\% of the businesses surveyed ranged between 1 and 5 years, indicating the relative start-up phase of the SMEs. SMEs confirmed the use of business skills acquired through ABSA ED training seminars. Although findings reflect positive impact on the growth of the SME, the Procurement Portal product reflects low growth impact. A link was found between business strategy and SME growth, where the use of ABSA ED had medium correlation, while business development correlated negatively to business growth.
\end{abstract}

Keywords: Growth, Enterprise Development, Small and Micro Enterprise

\section{Introduction}

The aim of the research was to test how effective the ABSA ED service was in assisting their client SMEs who are willing to learn and participate in the programme, in growing their businesses, being competitive and developing business strategy. A learning-oriented firm can easily grow in relation to other firms which choose not to continuously learn. Research has proven that the educational level of business owners has a positive association with business performance and growth [17] [24] [41]. In a recent study entitled "Understanding the rise of African business" [39], the researchers reviewed possible drivers of African enterprise growth, contingent on external and internal factors. They found that the contingent factors in SME growth ought to be examined with multiple lenses and not merely with a single view. This current research study determines the growth impact of SMEs from multiple factors, i.e. competition, strategy and business environment. SMEs are expected to play a critical role in South Africa's job creation efforts [31]; hence it is vital to track their progression and growth. SME growth depends on the managerial resources available over time to plan and manage growth in addition to maintaining current operations [40]. The study conducted by Hay, quoted in Mitra \& Pingali [41], concluded that it is internal rather than external barriers that impact the growth rate of an enterprise in the long term. In the same study, the key internal growth constraint is managerial capacity and the unwillingness on the part of the owner/manager to incur the 
risk associated with growth.

ABSA Enterprise Development (ABSA ED) is a division within Barclays Africa Group Limited with the mandate to assist SME growth and development. ABSA ED realises that SMEs need more than marketing of their services; they need business opportunities that they can execute successfully. In order to realise their growth objectives, SMEs need access to business opportunities, funding and business support [2]. Banks no longer provide just basic services. They have reassessed their strategic positioning of services and determined the strategic fit to clientele's needs [38]. The right balance between service offering and clients' needs is critical for success. ABSA ED is an additional optional service to ABSA SME clients. SMEs banking with ABSA and interested in the use of ABSA ED are offered free training, business networking opportunities and free basic registration on the ABSA ED Procurement Portal. This registration permits SMEs to show brief business information, including their company name, main business and contact details. SMEs using the free basic registration are unable to view tender opportunities.

SMEs are facing growth challenges due to a high percentage $(84.4 \%)$ of loan rejections from banks [25]. The barrier to accessing finance inhibits growth and sustainable business opportunities for SMEs [31]. Access to skills has been cited as one of the growth barriers [38]. ABSA ED does not only address the issue of access to markets, but also offers business support as well as access to finance. The support activities are directed at growing and developing the SME. It is clear that the ABSA ED offering is not operating with a profit objective; rather, it is more of a social responsibility initiative [1]. ABSA ED is resolving multiple challenges faced by SMEs in their growth path.

It follows that SMEs are intended to benefit from the ABSA ED service. The question arises whether SMEs that bank with ABSA and make use of ABSA ED are in fact growing their businesses. Owing to the investment in time, money and effort into the establishment and maintenance of Enterprise Development, it was crucial to determine the impact of the ABSA ED value offering on SMEs banking with ABSA and making use of ABSA ED. The impact of ABSA ED was assessed in relation to whether SMEs are growing or not.

\section{Problem Investigated}

Market access has been identified as one of the challenges hindering the growth of SMEs [4]. A recent study identified the causal effect of SME resources with specific reference to "competitive handicaps" which relate to entrepreneurs' lack of market connection and information necessary to grow the business [17]. It is rather concerning that in the age of information technology, SMEs still experience information asymmetry as a challenge hindering their development and growth. In a study conducted by the World Bank in 2007, in which three out of the four South African banks participated, it was found that South Africa had a high percentage
(69.39\%) of SMEs lacking access to loans [25] compared with other emerging countries. In another study it was documented that "SME development is hampered by lack of equipment, managerial skills, lack of finance and access to local and foreign markets" [30].

The growth and development of SMEs are necessary to achieve economic objectives while realising financial gains of the enterprise [19] [4] [25] [23]. There is an ongoing capital investment in running ABSA ED to support SMEs. The problem is that there is no measure of the impact of the ABSA ED value offering on SMEs banking with ABSA and making use of ABSA ED, and consequently on whether SMEs are growing or not.

\section{Research Objectives}

The primary research objective was to determine the impact of the ABSA ED service on the development and growth of the SMEs that bank with ABSA and make use of ABSA ED in the Gauteng region.

The secondary research objective was to identify and assess SMEs that are using the ABSA ED service and to determine their growth position by assessing business growth, competition, business strategy and business development.

\section{Literature Review}

The literature review focused on the strategic framework on which the study was based. A definition of SMEs as used in the study is given and the support intervention by ABSA ED to SMEs is explained.

\subsection{Strategic Management of Entrepreneurial Ventures Framework (SMEVF)}

The strategic framework for this research was based on several prior studies [4] [25] [22] [21]. The Mazzarol framework model [21] was adopted in this research due to characteristics which are similar to how ABSA ED was designed. ABSA ED recognises the importance of an informed entrepreneur, entrepreneurial orientation on innovation and training and how the opportunities are converted into sustainable businesses, which in essence cover the five steps of the SMEVF.

The research focused on assessing the growth impact on SMEs that ABSA ED has set to achieve. The SMEVF and ABSA ED have common constructs aimed at achieving sustainable business growth through the connection of opportunity recognition, resource accumulation and capacity building.

The SMEVF consists of five steps in relation to how they mirror the ABSA ED model [22]. The individual entrepreneur is prepared to take risks by recognising an opportunity to innovate. Regarding innovation, reference is made to the SME's ability to harness new ideas or determine new market entry to secure points of differentiation.

1. The strategic triangle entails the strategy of the firm, the 
appropriate structure that will be employed and the necessary resources to realise the strategy. This triangle helps SMEs to recognise the need to balance strategy with structure and resources. SMEs in their business plans are required to detail their strategy, structure and resources needed to grow their enterprises. The entrepreneur is linked to an ABSA ED consultant who plays an advisory role to refine the strategic triangle.

2. Strategic networks are about how the business establishes, maintains and grows relationships with other businesses [14]. Recent work by Omri \& AyadiFrikha [27] determined that managers with considerable human capital and social networks know where to look for opportunities and are better able to assess the value of potential opportunities. The ABSA ED seminars link SMEs to network partners that can ignite business growth.

3. The growth factor focuses on what the business growth plans look like. Can the SME select the product-market combinations for growth? The SME can choose to operate with the existing product and market, or venture into a new market with the same product, or innovate new products into the same market, or diversify altogether. An ABSA ED consultant partners with SMEs to realise their growth ambitions by providing advice on which funding model will assist SMEs in achieving their ambitions.

4. Sustainable growth over time is evidenced by turnover growth, growing employee numbers, stable employees (low staff turnover), asset growth and increases in market share, leading to overall growth in the business. Sustainable growth summarises the main research objective: To determine the impact of the ABSA ED value offering on the development and growth of SMEs that bank with ABSA and make use of ABSA ED in the Gauteng region.

The five steps are connected by the three-part entrepreneurial process of opportunity recognition, resource accumulation and capacity building [21] which follows the design of ABSA ED. The framework also sets the context of how the various constructs discussed in the literature review tie together with ABSA ED. The framework focuses on sustainable growth as an outcome.

\subsection{Small, Medium and Micro Enterprise Business Perspective}

The South African definition of SMMEs is officially documented in the White Paper on National Strategy for the Development and Promotion of Small Business in South Africa [12]. This working definition was adopted for the purpose and context of this study:

"a separate and distinct business entity, including cooperatives, enterprises and non-governmental organizations, managed by one owner or more which, including its branches or subsidiaries, if any, is predominantly carried on in any sector or subsector of the economy". The National Small Business Act categorises small businesses into distinct groups, namely survivalist, micro, very small, small and medium, and further classifies SMMEs according to industry. Medium businesses were excluded from the research study due to the bank segmentation process and focus of the study. The focus of the study was on small, very small and micro enterprises, and due to lack of an "appropriate" term, the term SME was used in this study. The following section deals with how ABSA ED supports SMEs.

\subsection{ABSA ED Support for SMES}

ABSA answered the government's call in 2012 with the establishment of the ABSA Enterprise Development division under Retail Business Bank. In summary, ABSA ED is about the following [2]:

Assisting and accelerating SME development - This is achieved through mentorship, educational workshops and training offered in ABSA's Enterprise Development centres.

Sustainable growth and development - The Procurement Portal acts as a matchmaker between suppliers of services (SMEs) and large corporates that demand services and products. It is intended that SMEs will land sustainable business opportunities from large corporates that in turn help to grow their businesses.

Bridging market access and access to finance - The various funds, including the Women's Empowerment Fund, Credit Fund and SME Fund which is capped at R250m per year, are intended for growing SMEs by facilitating lending.

The literature reviewed confirms that support is available for SMEs, but establishing whether SMEs are utilising this support is an area of study that needs to be confirmed or disproved [31] [8] [32]. To achieve the research objectives, the ABSA ED value offering was evaluated in terms of its impact on SME growth. The description of growth by ABSA ED is now discussed in relation to SME growth.

\subsection{Growth}

Dobbs and Hamilton [13] define growth as "a change in size over any given time period". Thus, a firm's rate of growth can be identified through linear interpolation between its observed size at the beginning and end of the period [15]. It is for this reason that the research study investigated SME growth over a period of a full year during which the SME had been with ABSA ED. Growth within the context of ABSA ED is evaluated through growth in revenue/profit, market share, employee numbers and business capacity and is viewed from its managerial implications and socio-economic impact on society.

In order to focus the discussion and meet the research objectives, factors affecting growth in SMEs were evaluated from both the internal and external environment by categorising questions into the following variables: competition, business development and sustainability and business level strategy. The growth indicators developed by Nieman [26] served as a key guideline when constructing the questionnaire. 


\section{Research Methodology}

The theory of how the research was undertaken is now described, including the theoretical and philosophical assumptions upon which the research was based and the implications of these for the methods adopted [28].

A quantitative research approach was adopted for this study due to its ability to produce results in numerical and standardised data, meaning derived from numbers and analysis conducted through the use of diagrams and statistics [28].

The larger population included SMEs that had made use of ABSA ED, or that had banked with ABSA and made use of ABSA ED in all regions in South Africa. The target population for the study was SMEs that banked with ABSA and had made use of ABSA ED within the Gauteng region.

The sample for the study was SMEs that had been banking with ABSA and making use of ABSA ED within the Gauteng region for a period of one year or more and that had made use of one or more ABSA ED services. The unit of analysis for this study was therefore SMEs that had banked with ABSA and made use of ABSA ED for a period of one or more years.

Purposive sampling was used to address specific purposes related to the research question. Tashakkori and Teddlie [35] describe critical case sampling as a purposive sampling technique that involves "selection of a single case that is particularly important to the understanding of a phenomenon because it permits maximum application of information". Critical case selection of SMEs that bank with ABSA and make use of ABSA ED in the Gauteng region was done due to Gauteng being the first region where ABSA ED was launched.

Data was collected through a survey questionnaire due to its ability to collect a large amount of data. The questionnaire was developed from an extensive literature review on the subject matter as well as input from subject matter experts who serve as ABSA ED executives. The questionnaire used dichotomous and a Likert scale format designed from the literature reviewed. It was divided into two sections. Section A gathered background information of the SME, while Section B gathered information relating to growth of the SME identified in interviews and the literature review section of the study. Four SMEs were consulted and served as a pilot for the study; their input assisted in further clarification of some questions which were not properly phrased or were unclear. Questionnaires were completed by owners of SMEs attending training sessions at ABSA ED centres, SME conferences organised by the South African Chamber of Commerce and Industry (SACCI), ABSA and Vodacom.

\section{Results/Findings}

Reliability "indicates the extent to which a measure is without bias" [29]. Cronbach's alpha was used to test reliability of the scale. Cronbach's alpha is a "coefficient measuring internal consistency and indicates how reliable a measurement is based on multiple items" [7].
Table 1. Reliability statistics.

\begin{tabular}{llll}
\hline & $\begin{array}{l}\text { Cronbach's } \\
\text { Alpha }\end{array}$ & $\begin{array}{l}\text { Cronbach's Alpha Based } \\
\text { on Standardised Items }\end{array}$ & $\begin{array}{l}\text { N of } \\
\text { Items }\end{array}$ \\
\hline Business growth & .805 & .804 & 4 \\
Competition & .873 & .870 & 14 \\
$\begin{array}{l}\text { Business strategy } \\
\begin{array}{l}\text { Business } \\
\text { development }\end{array}\end{array}$ & .875 & .874 & 13 \\
\hline
\end{tabular}

Table 1 reflects the internal consistency and reliability of the survey. The Cronbach's alpha measurement varies between 0 and 1, and according to Levin, Rubin, Stinson and Gardner [20], Cronbach's alpha above 0.7 is considered good. The internal reliability of the items for business growth, competition and business strategy were good at $.805, .873$ and .875 , respectively, but unacceptable at .580 for business development.

Results are discussed relating to the impact of ABSA ED on the growth of SMEs banking with ABSA and making use of ABSA ED within the Gauteng region. The main purpose of the research study was to understand and assess how the target beneficiaries (SMEs) are benefiting through the use of ABSA ED.

Table 2. Business growth.

\begin{tabular}{|c|c|c|c|c|}
\hline Business & Growth & Yes & No & Total \\
\hline \multirow{8}{*}{$\begin{array}{l}\text { Business } \\
\text { Growth }\end{array}$} & \multirow{2}{*}{$\begin{array}{l}\text { I am aware of the value added } \\
\text { products that ABSA Enterprise } \\
\text { Development (ED) have on } \\
\text { offer }\end{array}$} & 86 & 16 & 102 \\
\hline & & $84.3 \%$ & $15.7 \%$ & $100.0 \%$ \\
\hline & \multirow{2}{*}{$\begin{array}{l}\text { ABSA Enterprise products } \\
\text { improved the business sales/ } \\
\text { turnover in the past year }\end{array}$} & 52 & 48 & 100 \\
\hline & & $52.0 \%$ & $48.0 \%$ & $100.0 \%$ \\
\hline & \multirow{2}{*}{$\begin{array}{l}\text { I am able to identify the } \\
\text { improvement in the business } \\
\text { capacity since banking with } \\
\text { ABSA Enterprise }\end{array}$} & 67 & 32 & 99 \\
\hline & & $67.7 \%$ & $32.3 \%$ & $100.0 \%$ \\
\hline & \multirow{2}{*}{$\begin{array}{l}\text { I am able to use the business } \\
\text { advice received from ABSA ED } \\
\text { to help grow the business }\end{array}$} & 75 & 26 & 101 \\
\hline & & $74.3 \%$ & $25.7 \%$ & $100.0 \%$ \\
\hline
\end{tabular}

The strategic orientation of the enterprise mirrors the entrepreneurial and learning orientation of the owner/manager. Table 2 indicates the importance of the banker-SME relationship as the owner/manager gets to know the services that are available to enable their business growth; $74.3 \%$ of the respondents were able to use the advice received from the bank to help grow their business. $67.7 \%$ of the respondents could identify an improvement in their business capacity since banking with ABSA and making use of ABSA ED, while $32.3 \%$ indicated that they could not identify any improvement. 52\% could identify improvement in business sales or turnover, while $48 \%$ did not see any growth improvement. Overall, the business growth statistics amongst SMEs that responded showed a score of $50 \%$ or higher through the use of ABSA ED services. 
Table 3. Competition.

\begin{tabular}{|c|c|c|c|c|c|}
\hline Competition & & Yes & No & I Don't Know & Total \\
\hline \multirow{10}{*}{ Competition } & \multirow{2}{*}{$\begin{array}{l}\text { The business was able to record a higher sales/turnover growth than } \\
\text { competitors }\end{array}$} & 20 & 18 & 67 & 105 \\
\hline & & $19.0 \%$ & $17.1 \%$ & $63.8 \%$ & $100.0 \%$ \\
\hline & \multirow{2}{*}{$\begin{array}{l}\text { Last year the business achieved a higher growth on the number of } \\
\text { employees than our competitors }\end{array}$} & 26 & 25 & 54 & 105 \\
\hline & & $24.8 \%$ & $23.8 \%$ & $51.4 \%$ & $100.0 \%$ \\
\hline & \multirow{2}{*}{$\begin{array}{l}\text { The business has introduced more products than our competitors in the } \\
\text { past year }\end{array}$} & 26 & 46 & 32 & 104 \\
\hline & & $25.0 \%$ & $44.2 \%$ & $30.8 \%$ & $100.0 \%$ \\
\hline & \multirow{2}{*}{ Competitors in this market recognise us as leaders in innovation } & 18 & 39 & 47 & 104 \\
\hline & & $17.3 \%$ & $37.5 \%$ & $45.2 \%$ & $100.0 \%$ \\
\hline & \multirow{2}{*}{$\begin{array}{l}\text { The business has a written strategy on how we intend to grow the } \\
\text { business }\end{array}$} & 74 & 17 & 13 & 104 \\
\hline & & $71.2 \%$ & $16.3 \%$ & $12.5 \%$ & $100.0 \%$ \\
\hline
\end{tabular}

From Table 3 it is clear that SMEs lack awareness of competitors' moves in terms of product development, introductions or innovations. This was signalled by the high response of "I don't know" in the competition section. Entrepreneurial growth is about knowing the competitors' moves and attacking or defending to grow the business. The majority of SMEs did not know what their competitors' activities were. SMEs need to work more on identifying who their competitors are, what they are doing and how the enterprise can be better positioned to weather any competitive moves that can attack the SME business. This is clearly an area for development of the services of ABSA ED that should help SMEs to become more informed about their competitors.

Table 4. Business strategy.

\begin{tabular}{|c|c|c|c|c|}
\hline \multicolumn{2}{|c|}{ Business Strategy } & \multirow{2}{*}{$\begin{array}{l}\text { Yes } \\
84\end{array}$} & \multirow{2}{*}{ No } & \multirow{2}{*}{$\begin{array}{l}\text { Total } \\
106\end{array}$} \\
\hline \multirow{28}{*}{$\begin{array}{l}\text { Business } \\
\text { Strategy }\end{array}$} & \multirow{2}{*}{ We are willing to take risk that will enhance business growth } & & & \\
\hline & & $79.2 \%$ & $20.8 \%$ & $100.0 \%$ \\
\hline & \multirow{2}{*}{ We try new strategies even when we are not sure that they will always work } & 67 & 39 & 106 \\
\hline & & $63.2 \%$ & $36.8 \%$ & $100.0 \%$ \\
\hline & \multirow{2}{*}{ We are able to introduce new products } & 65 & 39 & 104 \\
\hline & & $62.5 \%$ & $37.5 \%$ & $100.0 \%$ \\
\hline & \multirow{2}{*}{ The business engaged in risky investments in the last year } & 27 & 79 & 106 \\
\hline & & $25.5 \%$ & $74.5 \%$ & $100.0 \%$ \\
\hline & \multirow{2}{*}{ Was the risky investment to stimulate future business growth } & 30 & 71 & 101 \\
\hline & & $29.7 \%$ & $70.3 \%$ & $100.0 \%$ \\
\hline & \multirow{2}{*}{ I am able to identify business trends that will enable the business to grow } & 88 & 18 & 106 \\
\hline & & $83.0 \%$ & $17.0 \%$ & $100.0 \%$ \\
\hline & \multirow{2}{*}{ We market our products to create need awareness to the target market } & 75 & 30 & 105 \\
\hline & & $71.4 \%$ & $28.6 \%$ & $100.0 \%$ \\
\hline & \multirow{2}{*}{ We have focused marketing efforts } & 65 & 39 & 104 \\
\hline & & $62.5 \%$ & $37.5 \%$ & $100.0 \%$ \\
\hline & \multirow{2}{*}{ We work to find new business and markets to target } & 85 & 19 & 104 \\
\hline & & $81.7 \%$ & $18.3 \%$ & $100.0 \%$ \\
\hline & \multirow{2}{*}{ We try to discover additional needs our customers have which they are unaware of } & 71 & 34 & 105 \\
\hline & & $67.6 \%$ & $32.4 \%$ & $100.0 \%$ \\
\hline & \multirow{2}{*}{$\begin{array}{l}\text { We ask what types of workshops ABSA Enterprise Development has that will help } \\
\text { improve the business }\end{array}$} & 44 & 61 & 105 \\
\hline & & $41.9 \%$ & $58.1 \%$ & $100.0 \%$ \\
\hline & \multirow{2}{*}{ We consider the business as being innovative } & 74 & 28 & 102 \\
\hline & & $72.5 \%$ & $27.5 \%$ & $100.0 \%$ \\
\hline & \multirow{2}{*}{ We try to be creative when solving problems } & 91 & 12 & 103 \\
\hline & & $88.3 \%$ & $11.7 \%$ & $100.0 \%$ \\
\hline & \multirow{2}{*}{ The business is often the first to market new products and services } & 37 & 66 & 103 \\
\hline & & $35.9 \%$ & $64.1 \%$ & $100.0 \%$ \\
\hline
\end{tabular}

According to Table 4, the business strategies of the SMEs surveyed are well developed. SMEs are aware of the importance of clearly articulating their strategies. The findings of the study reveal that SMEs pursue a specialisation growth strategy. This is consistent with the components of the single-business organisation strategy of Thompson, Strickland and Gamble [36] and the stages of small business growth of Hatten [18]. A specialisation strategy allows exploitation of current resources and capabilities without taking many risks. This is further confirmed by a mere $35.9 \%$ 
indicating that they were often the first to market new products and services, with $64.1 \%$ negative responses to this question. The choice of strategy informs the resource requirements and risks and therefore the decision framework for the growth method [11]. These findings are consistent with those of Suklev and Rexhepi [34], who say that the scale and scope of the SME operations often direct the strategy pursued. Regarding risk tolerance of SMEs, $74.5 \%$ highlighted that they had not engaged in risky ventures in the last year, but $25.5 \%$ had. The capital constraint highlighted by previous studies could be the reason for SMEs being risk averse as funds are required to take further risk [33] [6].

Table 5. Business development.

\begin{tabular}{|c|c|c|c|c|}
\hline & Business Development & Yes & No & Total \\
\hline \multirow{9}{*}{$\begin{array}{l}\text { Business } \\
\text { Development }\end{array}$} & \multirow{2}{*}{ I view continuous learning as an essential for business growth } & 102 & 3 & 105 \\
\hline & & $97.1 \%$ & $2.9 \%$ & $100.0 \%$ \\
\hline & \multirow{2}{*}{$\begin{array}{l}\text { I am actively involved in attending workshops that Absa Enterprise Development offers that } \\
\text { will add value to the business }\end{array}$} & 58 & 47 & 105 \\
\hline & & $55.2 \%$ & $44.8 \%$ & $100.0 \%$ \\
\hline & \multirow{2}{*}{$\begin{array}{l}\text { I have used the skills obtained through training workshops offered by ABSA Enterprise } \\
\text { Development }\end{array}$} & 71 & 33 & 104 \\
\hline & & $68.3 \%$ & $31.7 \%$ & $100.0 \%$ \\
\hline & I would recommend the ABSA training workshops to SMEs in my industry & 79 & 26 & 105 \\
\hline & \multirow{2}{*}{ I am attending other training workshops that are not offered by ABSA } & 56 & 47 & 103 \\
\hline & & $54.4 \%$ & $45.6 \%$ & $100.0 \%$ \\
\hline
\end{tabular}

The impact of ABSA ED is positive for business development amongst the SMEs surveyed. To develop the business while growing it at the same time, Dai, Maksimov, Gilbert and Fernhaber [10] also recommend that the costbenefit framework be applied to highlight the trade-offs associated with developing key personnel in an enterprise. ABSA ED aims to contribute to capacity development by empowering SMEs to realise their potential and use the capabilities to grow their businesses. Omri and Ayadi-Frikha [27] identified business development as a significant predictor of micro enterprise growth. From Table 5 it can be seen that $54.4 \%$ of respondents also highlighted that they were attending other training workshops that were not organised by ABSA, indicating a quest for knowledge to grow the enterprise.

\section{Inter-item correlation}

Scatter graphs present the inter-item correlation matrix which attempts to measure association between multiple variables. For the purpose of this research, use of ABSA ED, business strategy and business development were measured and correlated. According to Albright, Winston and Zappe [5], correlation literally means to co-relate and measure a relationship between two or more variables. A correlational coefficient typically ranges between -1.0 and +1.0 and provides intensity and direction. Intensity refers to the strength of the relationship and is expressed as a number 0 meaning no correlation exists, and 1 meaning a perfect correlation. Direction refers to how one variable moves in relation to the other [5]. A positive correlation or direct relationship means that two variables move in the same direction, and the direction can be up or down. Saunders et al. [28] explain that the magnitude of $r$ indicates the strength of the relationship:

$r=1$ : Very strong positive linear relationship between $X$ and $\mathrm{Y}$. $\mathrm{Y}$ increases as $\mathrm{X}$ increases.

$r=0$ : No linear relationship between $X$ and $Y$. $Y$ does not tend to increase or decrease as $\mathrm{X}$ increases.

$r=-1$ : Very strong negative linear relationship between $X$ and $\mathrm{Y}$. Y decreases as $\mathrm{X}$ increases.

Cohen (1988) provides more clarity on the meaning of $r$ :

$\mathrm{r}=.10$ (small effect)

$\mathrm{r}=.30$ (medium effect)

$\mathrm{r}=.50$ (large effect)

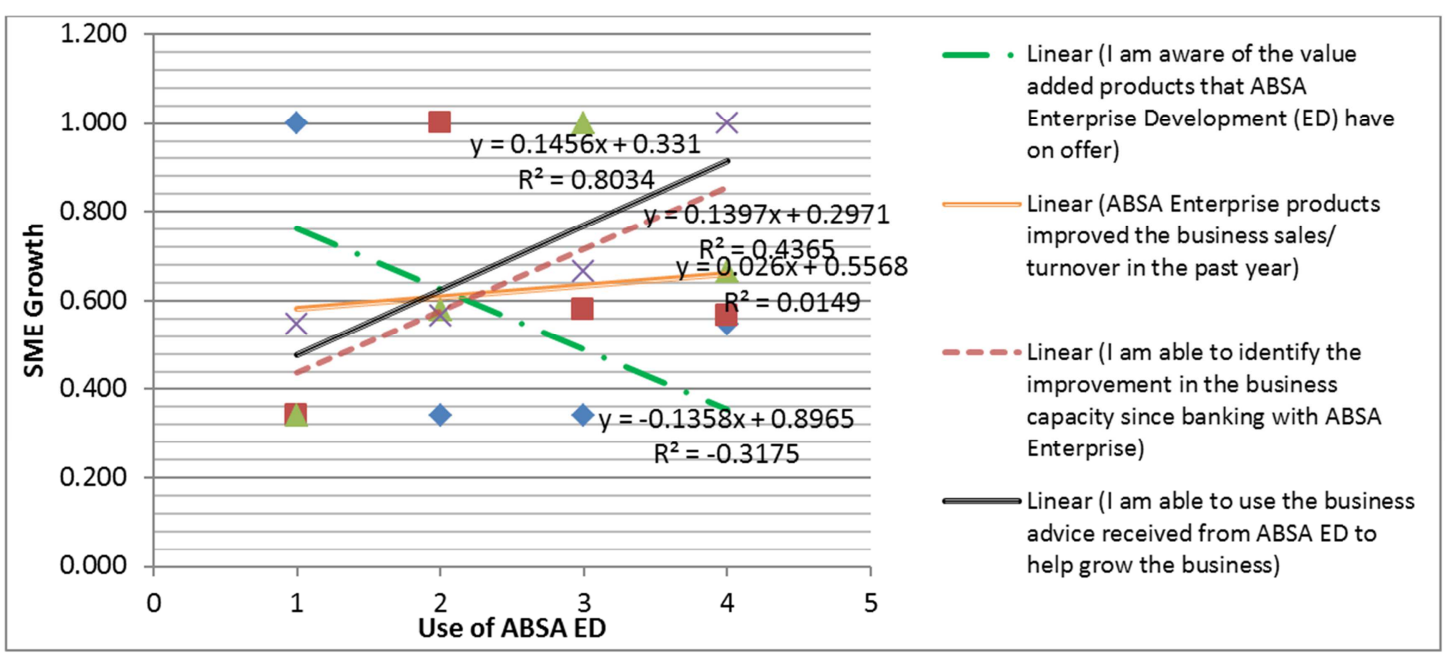

Figure 1. Use of ABSA ED and SME growth 
In Figure 1 a scatter plot graph has been used to assess the correlation between the use of ABSA ED (X variable horizontal axis) and SME growth (Y variable - vertical axis). In this section the researcher was interested in establishing whether the use of ABSA ED (independent variable) was linked to SME growth (dependent variable).

Four items were ranked and correlated to SME growth. A strong positive and large correlation of .8034 was seen for business advice SMEs received to grow the enterprises. Improvements noticed since SMEs had been banking with ABSA and making use of ABSA ED showed a medium positive correlation of .4365 . The findings confirm the $48 \%$ response indicated on improved business/sales turnover recorded in the last year regarding descriptive statistics. A weak positive and small correlation in ABSA ED products improving business sales/turnover was recorded at .0149. A negative correlation of -.3175 was recorded for SMEs' awareness of how ABSA ED can help grow the business, which shows the strength of the relationship between the items to be weak. The weak correlation contradicts the $74.3 \%$ response regarding descriptive statistics that SMEs were able to use business advice to help grow the business.

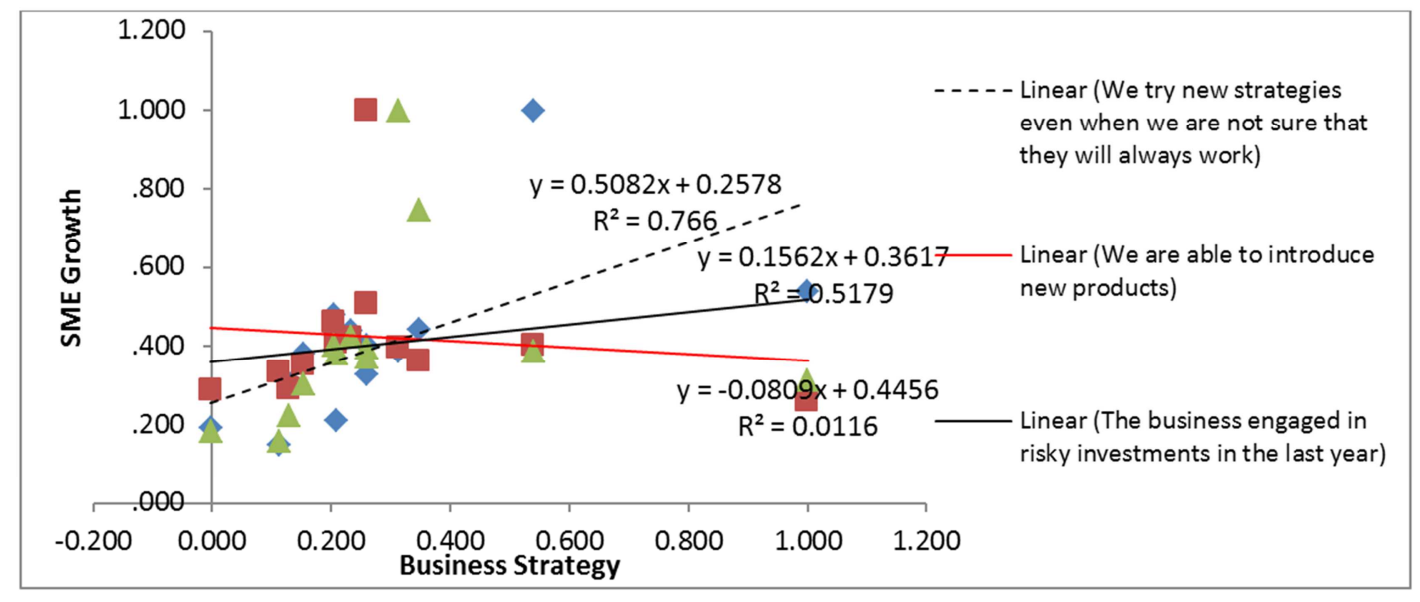

Figure 2. Business strategy correlated to SME business growth.

Figure 2 shows how SME business growth is correlated to the SME business strategy. The number of case items has been filtered to highlight the most important section in determining business strategy. There is a weak relationship between introducing new products and business growth; the recorded correlation is .1, which is a small effect. This ties in with the $64.1 \%$ response on being the first to market new products/services. Risky investment is indicated by a large effect correlation of .5179 to SME growth. There is a strong relationship between trying new strategies and SME growth, with a large effect of .766. Business strategy is therefore strongly correlated to SME growth. This is further emphasised by business strategy descriptive statistics which highlight how SMEs'strategy is well-articulated.

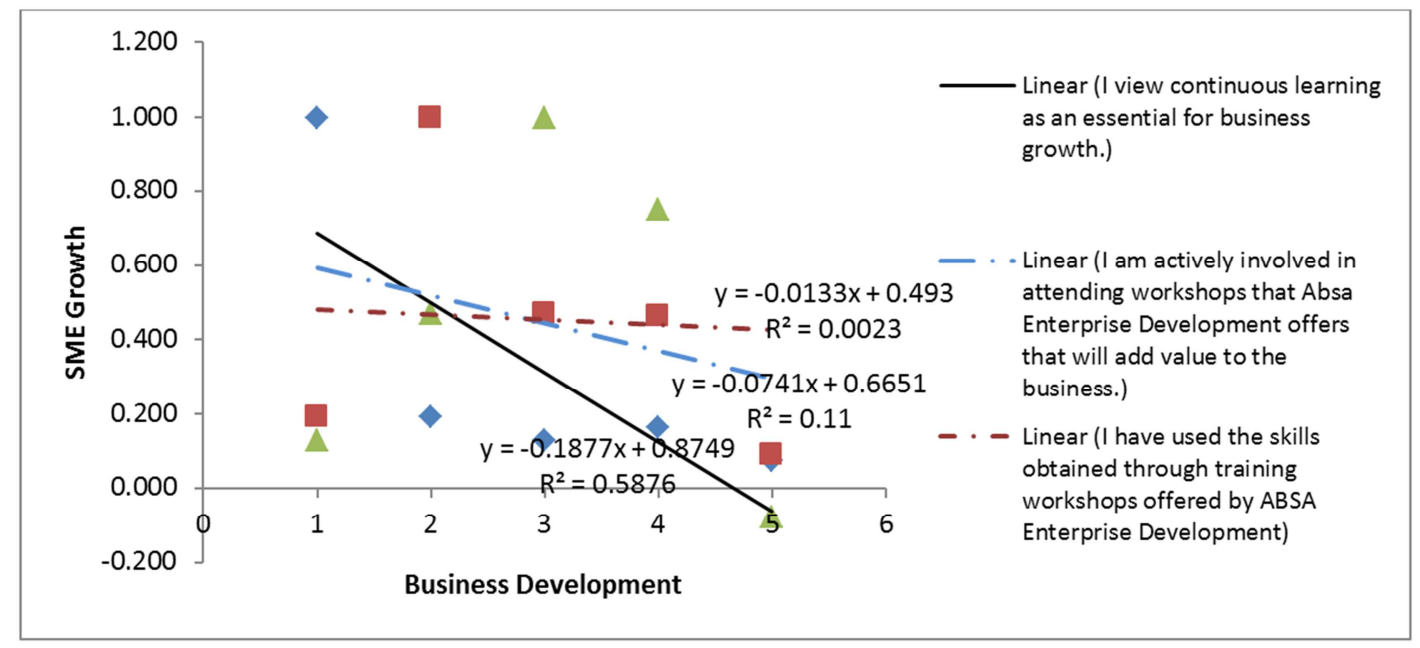

Figure 3. Correlation of business development to SME growth.

Figure 3 indicates a medium negative correlation between continuous learning and business growth; $r=0.5876$, which rejects the notion that continuous learning will correlate to business growth. The findings support those of Millan,
Congregado, Roman, Van Praag and Van Stel [24], who indicate a negative correlation between business development and growth of the SME owing to investment and time spent on development while not focusing on 
business expansion and growth plans. Respondents' attendance of ABSA ED training as adding value to the business is negatively correlated with SME business growth; $r=0,11$ is considered a small effect. Respondents' views on continuous learning as essential for business growth is almost not correlated; the score effect is small at $r$ $=0.0023$. Although it is important to attend training and development sessions, time taken away from the business can impact growth in the short term. It is therefore paramount to balance time spent on training and involvement in the actual running of the business.

\section{Conclusions}

The objective of this research was to determine the impact of ABSA ED on SME growth by assessing business growth, business strategy, competition and business development/sustainability. The study confirmed the growth of an SME from assessing the entrepreneurial orientation to growth, the strategy and the performance of the firm. Although a positive impact of ABSA ED on SME growth has been established, more can be done to further impact growth of the enterprise. SMEs are advised to implement the SMEV framework [21] in order to grow into sustainable enterprises. They can ensure alignment of opportunity recognition, resource accumulation and capacity building, with the end result being growth and sustainability for the enterprise.

\section{Managerial Applications}

In order to have more impact on the stakeholders involved in ABSA ED, the following are recommended:

- Competitive strategies should be developed by SMEs as this is important for sustainability in the future. Findings indicated lack of awareness of competitor moves.

- In order to grow, SMEs' risk tolerance needs to improve, and they need to take calculated risks rather than avoiding risk altogether. The response rate of $74.5 \%$ SMEs that did not engage in risky investments in the past year is concerning.

- SMEs need to implement a cost-benefit framework highlighting the trade-offs associated with developing key personnel in an enterprise to address business development correlation to SME growth findings.

- ABSA ED can improve on its service offering. The negative correlation recorded on ABSA ED awareness of business growth in relation to growth indicates that there is room for improvement to strengthen SME awareness in relation to how ABSA ED can enable growth.

\section{References}

[1] ABSA. Annual Report. Available from http://www.absa.co.za, 2013.
[2] ABSA. Enterprise Development. Available from http://intranet.intra.absa.co.za/retailbanking/ed/Pages/default.a spx, 2014a.

[3] ABSA. Funding for Enterprise Development - ABSA Enterprise Development. Proceedings of conference held in Klerksdorp, SME Business Summit, 2 October 2014. Conducted by ABSA, SEDA, South African Chamber of Commerce, Vodacom, 2014b.

[4] Adjasi, C. \& Rantseli, P. The role of procurement in promoting historically disadvantaged SMME's: Evidence from Ekurhuleni Municipality. Master's dissertation. Stellenbosch: Stellenbosch University, 2011.

[5] Albright, S. C., Winston, W. L. \& Zappe, C. Data Analysis \& Decision Making. 3rd Edition. Ohio: Thomson South-Western, 2006.

[6] Armstrong, C. E. Competence or flexibility? Survival and growth implications of competitive strategy preference among small US business. Journal of Strategy and Management, 6 (4): 377-398, 2013.

[7] Blumberg, B. F., Cooper, D. R. \& Schindler, P. S. Business Research Methods. 4th Edition. London: McGraw Hill, 2014.

[8] Chen, L., Danbolt, J. \& Holland, J. Rethinking bank business models: The role of intangibles. Accounting, Auditing and Accountability Journal, 27 (3): 563-589, 2014.

[9] Cohen, J. Statistical Power Analysis for the Behavioural Sciences. 2nd Edition. New York: Academic Press, 1988.

[10] Dai, L., Maksimov, V., Gilbert, B. A. \& Fernhaber, S. A. Entrepreneurial orientation and international scope: The different roles of innovativeness, proactiveness, and risktaking. Journal of Business Venturing, 29: 511-524, 2014.

[11] De Urbina-Criado, M., Guerras-Martin, L. A. \& MontoroSanchez, A. The choice of growth method: Strategies and resources. Academia Revista Latinoamericana de Administration, 27 (1): 30-45, 2014.

[12] Department of Trade and Industry (DTI). White Paper on National Strategy for the Development and Promotion of Small Business in South Africa. Notice No. 213 of 1995. Pretoria: Government Printer, 1995.

[13] Dobbs, M. \& Hamilton, R. T. Small business growth: Recent evidence and new directions. International Journal of Entrepreneurial Behavior and Research, 13 (5): 296-322, 2007.

[14] Edelman, L. F., Brush, C. G. \& Manolova, T. Co-alignment in the resource-performance relationship: Strategy as mediator. Journal of Business Venturing, 20 (3): 359-583, 2005.

[15] Eggers, F., Kraus, S., Hughes, M., Laraway, S. \& Snycerski, S. Implications of customer and entrepreneurial orientations for SME growth. Journal of Management Decision, 51 (3): 524546, 2013.

[16] Field, A. Discovering Statistics using IBM SPSS Statistics. 4th edition. London: Sage, 2013.

[17] Furlan, A., Grandinetti, R. \& Paggiaro, A. Unveiling the growth process: Entrepreneurial growth and the use of external resources. International Journal of Entrepreneurial Behaviour \& Research, 20 (1): 20-41, 2014. 
[18] Hatten, T. S. Principles of Small Business Management. 5th Edition. Boston: South-Western Cengage Learning, 2012.

[19] Laukkanen, T., Nagy, G., Hirvonen, S., Reijonen, H. \& Pasanen, M. The effect of strategic orientations on business performance in SMEs. International Marketing Review, 30 (6): 510-535, 2013.

[20] Levin, R. I., Rubin, D. S., Stinson, J. P. \& Gardner, Jr E. S. Quantitative Approaches to Management. 8th Edition. New York: McGraw-Hill, 1992.

[21] Mazzarol, T. A proposed framework for the strategic management of small entrepreneurial firms. Small Enterprise Research: The Journal of SEAANZ, 13 (1): 37-53, 2005.

[22] Mazzarol, T. W. \& Rebound, S. The Strategy of Small Firms: Strategic Management and Innovation in the Small Firm. Boston: Edward Elgar, 2009.

[23] Mazzarol, T. W. \& Rebound, S. Strategic Innovation in Small Firms. Boston: Edward Elgar, 2011.

[24] Millan, J. M., Congregado, E., Roman, C., Van Praag, M. \& Van Stel, A. The value of an educated population for an individual's entrepreneurship success. Journal of Business Venturing, 29: 612-632, 2014.

[25] National Credit Regulator (NCR). Literature Review on Small and Micro Enterprises' Access to Credit and Support in South Africa. Available from http://www.seda.org.za, 2011.

[26] Nieman, G. Small Business Management: A South African Approach. Pretoria: Van Schaik, 2006.

[27] Omri, A. \& Ayadi-Frikha, M. Constructing a meditational model of small business growth. International Entrepreneurial Management Journal, 10: 319-324, 2014.

[28] Saunders, M., Lewis, P. \& Thornhill, A. Research Methods for Business Students. 6th edition. London: Prentice Hall, 2012.

[29] Sekaran, U. \& Bougie, R. Research Methods for Business. 6th edition. London: Wiley, 2013

[30] Scarborough, N. M. Effective Small Business Management: An Entrepreneurial Approach. 10th Edition. New York: Pearson, 2012.
[31] Small Business Project (SBP). Growth and Competitiveness for Small Business in South Africa. Available from www.sbp.org.za, 2014.

[32] Small Enterprise Development Agency (SEDA). Analysis of the Needs, State and Performance of Small and Medium Businesses in the Agriculture, Manufacturing, ICT and Tourism Sectors in South Africa. Mthente Research and Consulting Services. Available from http//:www.seda.org.za, 2012.

[33] Soppe, B., Lechner, C. \& Dowling, M. Vertical competition in entrepreneurial firms: Theory and practice. Journal of Small Business and Enterprise Development, 21 (4): 1-31, 2014.

[34] Suklev, B. \& Rexhepi, G. Growth Strategies of Entrepreneurial Businesses: Evidence From Macedonia. Entrepreneurship in the Balkans, 1: 77-87, 2013.

[35] Tashakkori, A. \& Teddlie, C. Mixed Methodology. London: Sage. Tinnila, M. (2013). Efficient service production: Service production in banking. Business Process Management Journal, 19 (4): 648-661, 2009.

[36] Thompson Jr. AA, Strickland III AJ, \& Gamble JE. Crafting and executing strategy: Text and reading. (18th Ed). New York: McGraw-Hill Irwin, 2010.

[37] Tinnila, M. (2013). Efficient service production: Service production in banking. Business Process Management Journal, 19 (4): 648-661.

[38] Veselinova, E. \& Samonikov, M. G. SMEs innovation and growth in EU. Management Journal for Theory and Practice Management, 64: 87-94, 2012.

[39] Tvedten, K., Wendelboe, M. \& Jeppesen, H. S. (2014). Understanding the rise of African Business. African Journal of Economic and Management Studies, 5 (3): 249-268.

[40] Orser, B. J., Hogarth-Scott, S. \& Riding, A. L. (2000). Performance, firm size, and management problem solving. Journal of Small Business Management, 38 (4): 42-58.

[41] Mitra, R. \& Pingali, V. (2009). Analysis of growth stages in small firms: A case study of automobile ancillaries in India. Journal of Small Business Management, 1: 69-75. 